International Journal of Advanced Academic Research (Social and Management Sciences) | ISSN: 2488-9849

Vol. 6, Issue 11 (November, 2020)|www.ijaar.org

Journal DOI: 10.46654/ij.24889849

Article DOI: 10.46654/ij.24889849.s6121012

\title{
HOUSEHOLD ENERGY CONSERVATION, WASTE AND WATER MANAGEMENT PRACTICES IN PORT HARCOURT METROPOLIS, RIVERS STATE
}

\author{
Ohanuna, C. ${ }^{1 *}$ and Nwanyanwu, K.C. ${ }^{2}$
}

1. Department of Environmental Management, University of Port Harcourt, Choba.

2. Department of Public Health, Federal University of Technology, Owerri.

*Corresponding Author: Ohanuna, $\mathrm{C}^{1}$. ohanunachukwudi@yahoo.com

\begin{abstract}
The study examined household energy conservation, waste and water management practices in Port Harcourt Metropolis. The study adopted both primary and secondary sources of data collection. A total of 11 communities were selected through simple random sampling using the balloting technique while 396 respondents were selected across the target communities using the Taro Yamane and proportion allocation method. The study identified proper bagging and making use of designated waste disposal locations as the predominant household waste management practice. In addition, $40.2 \%$ of the sampled population made use of energy saving bulbs and appliances as against 59.8\% who do not use energy conserving bulbs and appliances. The study also revealed that $45.1 \%$ attributed low income and financial earnings while $29.1 \%$ attributed insufficient waste storage and disposal containers as the major factors associated with unsustainable household practices. Finally the tested hypotheses at $95 \%$ probability level revealed that income and educational status significantly influenced household waste management practice and energy usage respectively. Therefore, the study recommends that adequate awareness against unacceptable household practice like indiscriminate waste disposal should be undertaken.
\end{abstract}

Keywords: Environment; Health; Household; Sustainability; Waste 


\section{Introduction}

The dangers of climate change have placed environmental sustainability precisely at the focal point of the policy agenda. Governments around the world, including Nigeria, are evolving policies targeted at minimizing carbon emissions and fostering sustainable practices. Clearly, change is imperative at all levels, including the international, intra-national, institutional, household and on an individual level. Nigeria's per capita greenhouse gas emissions have become increasingly high (United Nations Development Programme, 2001) and households also contribute significantly to greenhouse gas emissions (Lawanson, 2006). Thus, the household in its discrete dwelling setting is a significant site for action. Household sustainability is a crucial factor with significant effect on the overall sustainability and resistivity of the world towards forthcoming environmental issues. The consumption pattern of different household varies, but the sustainability of the consumption can only be established when the consumption of the household is evaluated (Mishra, 2006).

However, despite government programs and awareness campaigns on the necessity for a sustainable environment through personal and household actions, environmental sustainability has continued to be mirage even in developed countries (O'Neill and Chen, 2002). Port Harcourt metropolis presents a horrific picture; the abandonment of filled refuse bins in recent times has had its effect on the environment. Many areas around the homes are littered with domestic refuse and sewage waste. These wastes are toxic with negative impacts on the environment; land, water and air (Ayuba et al., 2013). In addition, residents are ignorant of the dangers of uncontrolled usage of water, energy and other natural resources.

To ensure a sustainable environment, the Rivers State Government established the Rivers State Environmental Sanitation Authority (RSESA) and the Rivers State Waste Management Authority (RIWAMA) but their efforts seem not to have altered the unsustainable practices by household to unlawfully dispose their domestic waste at places they adjudge to be very convenient to them and this subsequently leads to an increase in diseases like malaria fever, typhoid fever and dysentery. Public enlightenment/ awareness programs that promote energy and water-efficient practices are not existent and there is no appropriate authority to monitor water and energy conservation (Opara, 2009).

These have resulted to a dire need to understand how to facilitate more productive use of energy through installation of devices that promote energy conservation and efficiency and through changed household practices. In line with this need, the Nigerian government has instituted policies aimed at promoting household sustainability such as the renewal energy policy programs (Chigbue, 2006). While these policies and programs represent a positive advancement towards promoting household sustainability, more investigations are required to fully understand how we can move Nigerian households towards sustainability. There is therefore a need to understand current household energy conservation, waste and water management practices of Nigerian households with a view to identifying the key elements that aid or undermines engagement in these practices.

It is also imperative to comprehend how household sectors may differ in this area. Low income 
household have been objects of unsustainable practices (Olarenwaju, 2003). This assertion highlights the need, not only to develop an understanding of the various factors that underpin householders' energy conservation, waste and water management decisions, but also to explore the ways in which these decisions may be impacted by socio-demographic factors. In the light of these, the researcher embarked on this study to ascertain household energy conservation, waste and water management practices in Port Harcourt Metropolis.

\section{Materials and Method}

The study area, Port Harcourt metropolis is the capital of Rivers State is located between $04^{0} 43^{\prime}$ and $04^{0} 57^{\prime}$ 'North of the Equator and between longitude $06^{\circ} 53^{\prime}$ and $07^{0} 08^{\prime}$ East of the Greenwich Meridian (See Figure 1 below).

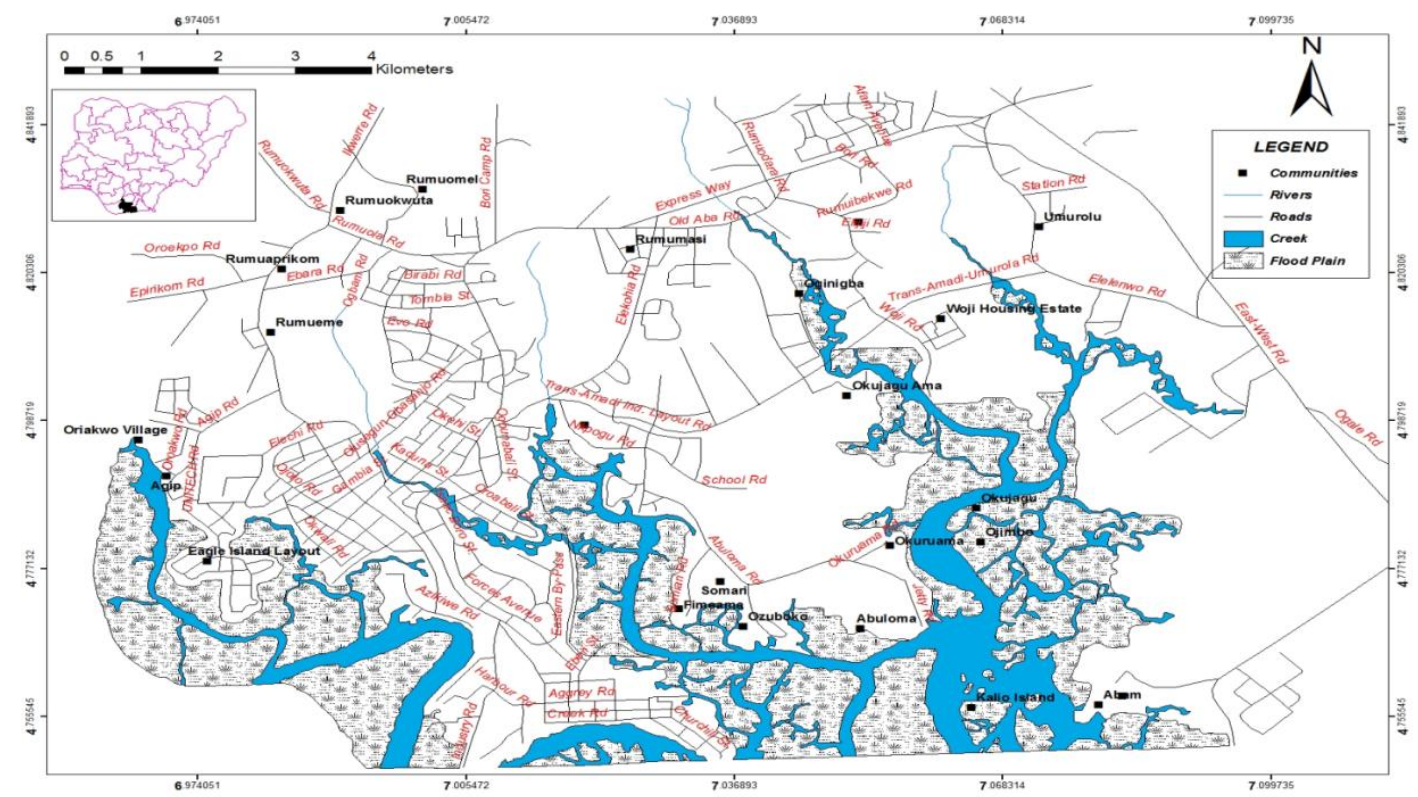

Fig. 1: Map of Port Harcourt Metropolis

Source: Cartography/GIS Laboratory, Department of Geography and Environmental Management, University of Port Harcourt, Choba.

The descriptive survey design was adopted for this study. Simple random sampling by balloting was used to select 11 communities out of 113 communities in the study area. From the population of the 11 selected communities a total of 36,494 households made up the sample strata. Finally, to achieve a manageable sample size from the total population, the Taro Yamane (1967) formula was applied to arrive at a cumulative sample size of 396 respondents for this study. For this study, a questionnaire was used to gather the needed primary data required. To achieve face and content validity, the research questionnaire was subjected to a review by other experts in the academia. The Cronbach alpha' equation was used to obtain the reliability index. The alpha coefficient of 0.787 , suggested that the research questionnaire had relatively high internal consistency and is therefore reliable. The study in analyzing the data obtained made use of descriptive statistics such as percentage distribution, charts and table techniques. The 
postulated hypotheses were tested using Chi-Square. The computer software Statistical Package for Social Sciences (S.P.S.S.) version 20.1 was employed for this analysis.

\section{Results}

Table 1 reveals the demographic and socioeconomic characteristics of respondents in the study area. The age distribution shows that $8.8 \%$ were within the ages of $16-20,17.9 \%$ were within the ages of $21-25,25.8 \%$ were within the ages of $26-30$ while $47.5 \%$ were within the ages of 31 and above. The gender distribution shows a cumulative of $48.7 \%$ and $51.3 \%$ were male and females respectively for the total strata. It was also revealed that $34.8 \%$ of the respondents were single and 53.3\% were married. The percentages of divorced, widowed and separated respondents were $1.3 \%, 4.5 \%$ and $6.1 \%$ respectively. Questionnaire analysis showed that 53\% had their first degree and other higher degrees, $15.4 \%$ of the respondents had their first school leaving certificate (FSLC), 23.5\% of the respondents had their senor school certificate (SSCE/O'level) while $8.1 \%$ of the respondents had no formal education. Table 1 also revealed that $34.3 \%$ of the respondents were earning above $\mathrm{N} 125,000,25.5 \%$ of them were earning between N96,000125,000 while $7.8 \%$ earned N76,000-N95,000. More so, $17.2 \%$ and $15.2 \%$ of the respondents do earn between N51,000-N75,000 and less than N50,000 respectively. 
Journal DOI: 10.46654/ij.24889849

Vol. 6, Issue 11 (November, 2020) | www.ijaar.org

Article DOI: 10.46654/ij.24889849.s6121012

Table 1: Demographic and Socio-economic Characteristics of Respondents

\begin{tabular}{ll}
\hline Variables & Frequency \\
\hline Age group (years) & $35(8.8 \%)$ \\
$16-20$ & $71(17.9 \%)$ \\
$21-25$ & $102(25.8 \%)$ \\
$26-30$ & $188(47.5 \%)$ \\
31 and above & \\
Sex & $193(48.7 \%)$ \\
Male & $203(51.3 \%)$ \\
Female & \\
Marital status & $138(34.8 \%)$ \\
Single & $211(53.3 \%)$ \\
Married & $5(1.3 \%)$ \\
Divorced & $18(4.5 \%)$ \\
Widowed & $24(6.1 \%)$ \\
Separated & \\
Educational Qualifications & $32(8.1 \%)$ \\
No formal education & $61(15.4 \%)$ \\
FSLC & $93(23.5 \%)$ \\
O' level/SSCE & $210(53 \%)$ \\
Bsc/higher degrees & \\
Income distribution & $60(15.2 \%)$ \\
Less than N50,000 & $31(7.8 \%)$ \\
N51,000-75,000 & $101(25.5 \%)$ \\
N76,000-95,000 & \\
Above N125,000 & \\
\hline
\end{tabular}

Figure 2 show that $49.2 \%$ of the respondents revealed that PHCN was the major energy source in the household, $23.0 \%$ of the respondents depended on solar power/ inverter as their major source of energy usage while $27.8 \%$ of the respondents used generators as their major source of energy 


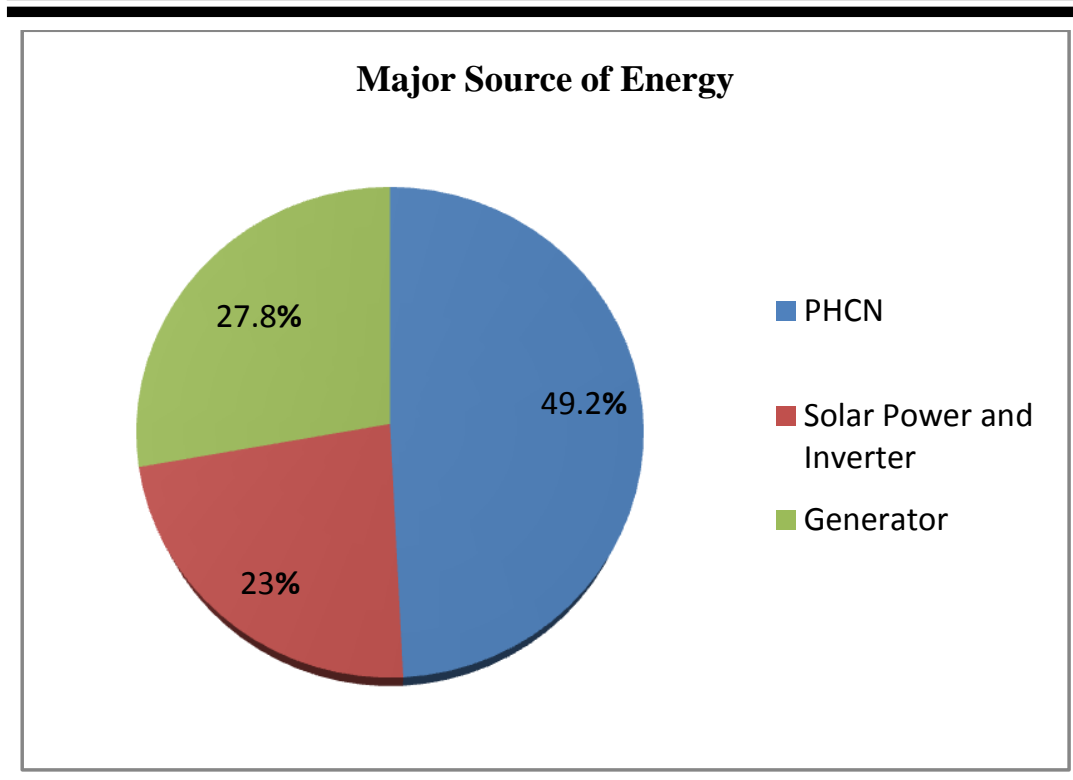

Fig 2: Major Source of Household Energy

Table 2 outlines the household energy conservation methods. Analysis of questionnaire responses revealed that $24 \%$ of the respondents switch off the lights when exiting the room as their method of household energy conservation, $19.7 \%$ made use of low energy bulbs and energy saving appliances, $29 \%$ of the respondents disconnected appliances when not in use, 10.4\% made use of inverter for alternative power while $16.9 \%$ of the respondents installed dimmer switches as their household energy conservation technique.

Table 2: Household Energy Conservation Methods

\begin{tabular}{lll}
\hline Household Energy Conservation Methods & Frequency & Percentage \% \\
\hline $\begin{array}{l}\text { Switching off the lights when leaving the room } \\
\begin{array}{l}\text { Use of low energy bulbs and energy conserving } \\
\text { appliances }\end{array}\end{array}$ & 95 & 24.0 \\
$\begin{array}{l}\text { Disconnecting appliances when not in use } \\
\text { Use of inverter for alternative power }\end{array}$ & 115 & 19.7 \\
Installation of dimmer switches & 41 & 29.0 \\
Total & 67 & 10.4 \\
\hline
\end{tabular}


Table 3 shows the household usage of low energy bulbs. The analysis of questionnaire revealed that $40.2 \%$ of the sampled population make use of energy saving bulb against $59.8 \%$ of the sampled population who do not use energy conserving bulbs

Table 3: Household Usage of Low Energy Bulbs

\begin{tabular}{lll}
\hline Option & Frequency & Percentage \\
\hline Yes & 159 & $40.2 \%$ \\
No & 237 & $59.8 \%$ \\
Total & 396 & $100 \%$ \\
\hline
\end{tabular}

Table 4 below outlines the household water conservation techniques. The analysis of questionnaire revealed that $34.3 \%$ of the respondents switch off their taps when not in use as an effective technique of household water conservation, $28.8 \%$ of the respondents repair their dripping taps to conserve water, $9.6 \%$ of the respondents installed water saving bathroom shower heads, $5.8 \%$ of the respondents conserved water by reducing shower time while $21.5 \%$ of the respondents employed the use of bowls and bailers as a means to conserve household water.

Table 4: Household Water Conservation Techniques

\begin{tabular}{lll}
\hline Household Water Conservation Techniques & Frequency & Percentage \% \\
\hline Switching off taps when not in use & 136 & 34.3 \\
Repair of dripping taps & 114 & 28.8 \\
$\begin{array}{l}\text { Installation of water saving bathroom shower } \\
\text { heads }\end{array}$ & 38 & 9.6 \\
$\begin{array}{l}\text { Reducing shower time } \\
\text { Use of bowls and bailers to store water }\end{array}$ & 23 & 5.8 \\
Total & 85 & 21.5 \\
\end{tabular}

Source: Author's computation

Figure 3 reveals that $85.4 \%$ of the total sampled population made use of septic tank to discard waste water while $14.6 \%$ of the total sampled population disposed their waste water into the public/ street drainage channel. 


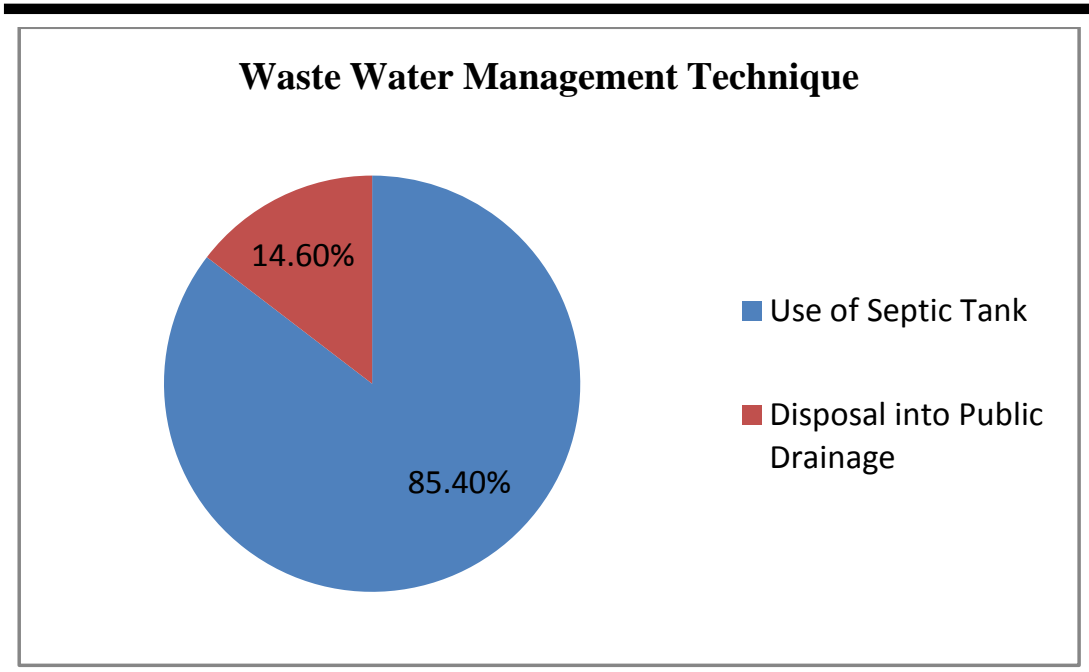

Fig 3: Waste Water Management Technique

Figure 4 below shows the methods of waste disposal. Questionnaire analysis revealed that $4.8 \%$ of the respondents bury their waste, $15.1 \%$ engage in street dumping, $59.8 \%$ dispose their waste in designated waste disposal points while $20.1 \%$ dispose household waste by open burning as illustrated in the figure below.

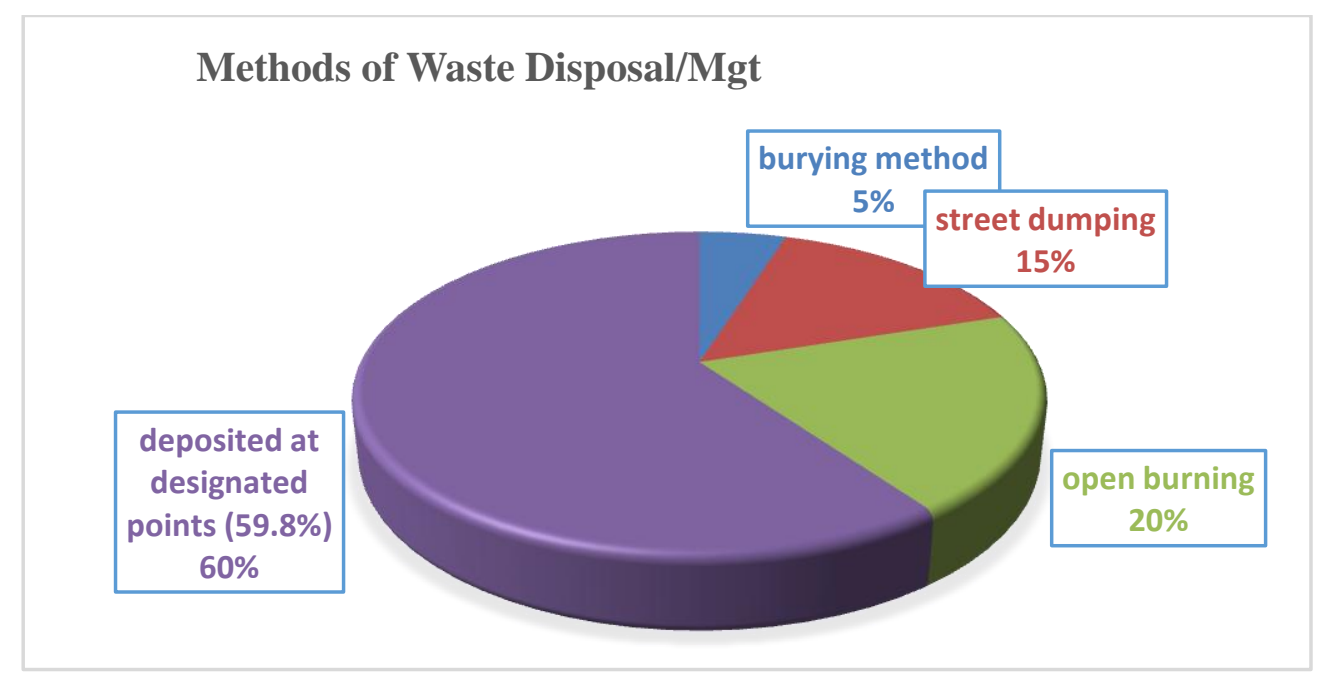

Fig 4: Methods of Waste Disposal

Figure 5below illustrates the factors responsible for unsustainable household practices. The questionnaire analysis shows that $50.7 \%$ of the total sampled populations attributed their household unsustainable practices to low income and financial earnings, $27.7 \%$ of the sampled population attributed unsustainable household practices to insufficient waste storage and disposal containers for their household disposal, $17.1 \%$ of the total sample population attributed lack of environmental awareness as a factor responsible for unsustainable household practices, $3 \%$ stated 
that inadequate government support was basely responsible for unsustainable household practices while $1.2 \%$ of the populace did not respond as illustrated below

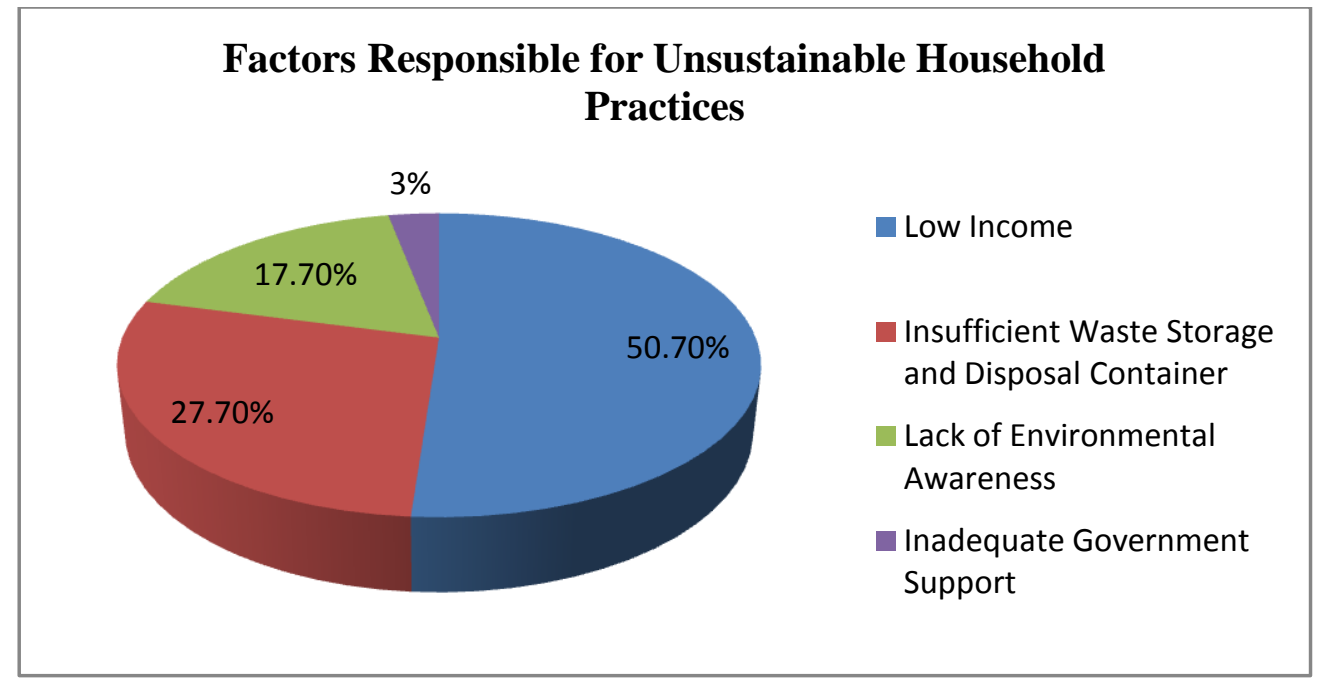

Fig 5: Factors Responsible for Unsustainable Household Practices.

\section{Hypotheses Testing \\ Ho $_{1}$ : There is no significant statistical relationship between educational status and household energy usage practices.}

In the analysis of $\mathrm{Ho}_{1}$, the $\mathrm{p}$ value of 0.001 which is less than 0.05 level of significance invariably means that the null hypothesis which states that there is no significant statistical relationship between educational status and household energy usage practices is rejected while the alternate hypothesis is upheld. This means that there is a significant statistical relationship between educational status and household energy usage practices. This invariably means that the educational status of the respondents significantly influenced sustainable household energy usage

\section{$\mathrm{Ho}_{2}$ : There is no significant statistical relationship between age group of respondents and water usage practices.}

In the analysis of $\mathrm{Ho}_{2}$, the $\mathrm{p}$ value of 0.284 which is greater than 0.05 invariably means that the null hypothesis which states that there is no significant statistical relationship between age group and household water usage practices is upheld while the alternate hypothesis is rejected. This means that there is no significant statistical relationship between age group and household water usage practices. This invariably means that the age group of the respondents did not significantly influence their household sustainable water usage practices. 
Hoz: There is no significant statistical relationship between income of respondents and waste management practices.

In the analysis of $\mathrm{Ho}_{3}$, the p value of 0.001 which is less than 0.05 invariably means that the null hypothesis which states that there is no significant statistical relationship between income of respondents and household waste management practices is rejected while the alternate hypothesis is upheld. This means that there is a significant statistical relationship between income of respondents and household waste management practices. This invariably means that household waste management practices are significantly influenced by income.

\section{Discussion}

The findings of this research observed that majority of the respondents have not come to terms with the use of low energy bulbs. This finding is in tandem to the findings of Adeyemo and Odukwe (2008). This could be attributed to the high cost of the low energy bulbs. Furthermore, the findings of this research revealed that the predominant technique of household energy conservation was achieved by switching off the lights when exiting the room in agreement to the findings of Lebot (2009). This study also revealed that the predominant technique of household water conservation in the study area was through switching off taps when not in use. This is in agreement to the findings of Randolph (2005) who revealed in his study that switching off taps, repair of dripping taps and the installation of shower control are the prevalent techniques of water conservation. The research findings also revealed that unsustainable household practices resulted from low income and financial earnings. This finding is in agreement to the findings of Lawanson (2006) who outlined low income of households as one the challenges facing the promotion of environmentally sustainable practices in the households. The research also revealed an influence of the educational status of the residents on household energy usage practices. This finding is in agreement to the findings of O'Neill and Chen (2002). Similarly, it was revealed from the research that the income of the residents significantly influenced their household waste management practices. This research finding is in tandem to the findings of Pinto et al. (2004). On the other hand, the research findings revealed that the age group of the respondents did not significantly influence sustainable household water usage practices. The finding is in agreement to the finding of Fielding et al. (2009) who in their separate study revealed that age does not influence sustainable household water usage. However, the findings of this research is in sharp contrast to the findings of Troy et al. (2005) who in their study revealed that age significantly influence household water usage.

\section{Conclusion}

It is obvious that managing solid waste, conserving water and energy has been a major issue in many African municipalities. This challenge has continued to raise numerous concerns even as rapid development in many growing cities of developing nations has compounded this issue. People are not unknowledgeable of the negative consequences of indiscriminate waste dumping or poor sanitation. However, the distant location of refuse receptacles are sometimes too far to the people for easy dumping of wastes and more often than not, there are insufficient waste disposal containers for waste gathering. In addition, low income and lack of government support 
Journal DOI: 10.46654/ij.24889849

Article DOI: 10.46654/ij.24889849.s6121012

has also led to indiscriminate dumping of wastes. Despite these constraints, majority of the households engaged in sustainable waste management practices such as proper bagging of wastes and disposing in designated waste points and composting.

Furthermore, sustainable energy conservation practices such as the use of low energy bulbs and switching off appliances when not in use have been put in place. Similarly, sustainable household water conservation has become imperative arising from the rising population and increased urbanization. Water conservation techniques such as the installation of flow control in taps, shower heads and repair of dripping taps have become necessary. 


\section{References}

Adeyemo, S.B. and Odukwe, A.O. (2008). Energy Conservation as a Viable Pathway towards Energy Stability. Journal of Engineering and Applied Sciences, 3(3), 233 - 238.

Ayuba, K.A., Manaf, L.A., Sabrina, A.H. and Azmin, S.W.N. (2013). Current Status of Municipal Solid Waste Management Practice in FCT Abuja. Res J Environ Earth Sci., 5, 295-304.

Chigbue, N.I. (2006). Reform of Electric Power Sector: Journey so far. A Lecture Delivered at the US Africa Collaboration Research Sponsored by the National Science Foundation in Abuja, Nigeria.

Fielding K. S., Louis, W. R., Warren, C. and Thompson A. (2009). Environmental Sustainability in Residential Housing: Understanding Attitudes and Behaviour Towards Waste, Water, and Energy Consumption and Conservation among Australian Households. AHURI Positioning Paper, Queensland Research Centre: Brisbane

Lawanson, T.O. (2006). Challenges of Sustainability and Urban Development in Nigeria: Reviewing the Millennium Development Goals. African Insight. Vol. 1

Lebot, B. (2009). Energy Efficiency and Market Transformation: A Short Overview of Best Practices. A paper presented during the Inception Workshop of the UNDP-GEF Project to Promote Energy Efficiency in Residential and Public Building in Nigeria, 14th July 2009

Mishra, A.K. (2006) Sustainable Resource Management, University of Limerick.

Olanrewaju, O.O. (2003). Waste to Wealth: A Case Study of the Ondo State Integrated Wastes Recycling and Treatment Project, Nigeria. Europ. J. Soc. Sci., 8(1), 7-16.

O'Neill, B. C., and Chen, B. S. (2002). Demographic Determinants of Household Energy Use in the United States. Population and Development Review, 28, 53-88.

Opara, J.A.(2009).Urban Waste Management in Port Harcourt Metropolis of the Niger Delta Region, Nigeria. Unpublished PhD Thesis, Universidad Central de Nicaragua, ManaguaNicaragua.

Randolph, B. (2005). Attitudes to Conservation and Water Consumption. Environmental Science and Policy, 11, 441-455.

Troy, P., Holloway, D. and Randolph, B. (2005). Water Use and Built Environment: Patterns of Water Use in Sydney. Retrieved August 15, 2018 from nts/researchpaper1.pdf

United Nations Development Programme (2001) Third United Nations Conference on the Least Developed Countries, Programme of Action for the LDCs. Retrieved October, 29, 2018 from www.unctad.org/en/docs/aconf191d11.en.pdf. 